\title{
Pandangan Multikultural Ki Padmasusastra Melalui Empat Karya Sastranya
}

\author{
Prasetyo Adi Wisnu Wibowo \\ Universitas Sebelas Maret Surakarta
}

\begin{abstract}
Abstrak
Ki Padmasusastra (1843-1926) yang sering menyebut dirinya dengan nama tiyang mardika ingkang marsudi kasusastran Jawi ing Surakarta adalah penulis dan pemerhati bahasa, sastra, dan budaya Jawa setelah era para pujangga Jawa. Ki Padmasusastra walaupun tertarik dan menerima norma-norma sastra dan budaya Eropa, akan tetapi ia tetap mengabdikan diri pada sastra dan budaya Jawa tradisional. Kehadiran empat karya sastranya memiliki warna dan keunikan tersendiri yang menempatkan Ki Padmasusastra sebagai salah satu pengarang Jawa yang terkenal. Pandangan-pandangan multikultural, pemikiran, kreativitas, maupun keteladanan semangat Ki Padmasusastra sebagai seorang pengarang telah berhasil membangun karakter bangsa melalui karya sastra.
\end{abstract}

Kata kunci: Ki Padmasusastra, karya sastra, pandangan multikultural.

\begin{abstract}
Ki Padmasusastra (1843-1926) is often called himself by the name tiyang mardika ingkang Marsudi kasusastran Jawi ing Surakarta is a writer and observer of language, literature, and culture of Java after the era of the poets of Java. Ki Padmasusastra although interested and accepted norms of European literature and culture, but he remains devoted to literature and traditional Javanese culture. The presence of four literary works have colors and unique that puts Ki Padmasusastra as one of the authors of the famous Java. The views multicultural, thinking, creativity, and the exemplary spirit of Ki Padmasusastra as an author has succeeded in building the character of the nation through literary works.
\end{abstract}

Keywords: Ki Padmasusastra, literature, multicultural outlook.

\section{PENDAHULUAN}

Ki Padmasusastra (1843-1926) adalah penulis dan pemerhati bahasa, sastra, dan budaya Jawa setelah era para pujangga Jawa antara lain Yasadipura I, Yasadipura II dan Ranggawarsita. Padmasusastra bukan seorang pujangga keraton, tetapi beliau banyak menghasilkan karya-karya besar seperti para pujangga keraton. Nama kecilnya adalah Suwardi, dan dikenal pula dengan nama Ngabei Kartadirana, Mas Gus Bei, Mas Ngabei Bangsayuda, Ngabei Kartipradata, Ki Padmasusastra, Ngabei Wirapustaka, Ki Prajapustaka (Wibowo, 2010: 113).

Ki Padmasusastra walaupun sejak kecil tidak pernah menikmati bangku sekolahan formal, akan tetapi Suwardi tetap belajar sendiri dengan arahan orang tuanya. Kemampuan Ki Padmasusastra dalam mengarang karya sastra tidak kalah dengan para pujangga sebelumnya (Mulyanto, 2003:2). Suwardi akhirnya mendapat kenaikan pangkat dari panewu, lalu sampai menjadi jaksa. Sudah menjadi kebiasaan bahwa ketika naik pangkat, keraton memberikan gelar atau nama baru bagi abdinya dan beliau mendapat sebutan Wirapustaka. Ketika dinaikkan pangkatnya menjadi panewu, beliau mendapat sebutan Prajapustaka pada tanggal 26 April 1920. Ketika menjadi jaksa berganti nama yaitu Kartipradata sampai beliau dipecat dari jabatannya dan setelah terjun di dunia kepengarangan berganti nama Ki Padmasusastra sampai wafatnya. 
Di Betawi, Ki Padmasusastra berguru kepada kepada seorang ilmuwan Belanda yaitu DF. van der Pant, seorang guru bahasa Jawa di Gymnasium Koning Willem III afdeeling $B$ di Meester-Cornelis. Kepandaian Ki Padmasusastra terhadap bahasa Jawa semakin terlihat. Ketika itu banyak sarjana dari luar negeri belajar mengenai bahasa Jawa kepada Ki Padmasusastra. Mereka kebanyakan para mahasiswa di Sekolahan Gymnasium Koning Willem III. Ki Padmasusastra bersama Tuwan D.F. van der Pant guru Gymnasium memberi tuntunan kepada para murid dalam melafalkan kosakata bahasa Jawa. Sejak saat itu Ki Padmasusastra menetap di Betawi serta banyak memiliki sahabat para sarjana dari Eropa. Sejak saat ini beliau mulai tertarik untuk melestarikan, meneliti bahasa, sastra dan budaya Jawa (Imam, 1961: 32).

Tuwan D.F. van der Pant setelah pulang ke negeri Belanda, Ki Padmasusastra juga pulang ke Surakarta. Beliau akan tetapi kembali lagi ke Betawi menjadi guru swasta yang mengajar bahasa Jawa. Keberadaan Ki Padmasusastra di Betawi tidak hanya untuk belajar dan bertukar pendapat dengan para sarjana Eropa, tetapi juga beliau di sana mengajar para murid.

Ki Padmasusastra berkat kemampuan menyerap ilmu dari berbagai buku, ia akhirnya menjadi orang yang pandai. Kepandaian membuat hatinya menjadi lebih halus, berpikir lebih hati-hati, tidak sombong, dan selalu berpikiran yang positif atau baik. Gagasan-gagasan baru yang sangat jarang dalam budaya Jawa mengalir dalam tema-tema karya sastra $\mathrm{Ki}$ Padmasusastra. Oleh karena itu tulisan ini akan membahas pandangan-pandangan multikultural Ki Padmasusatra melalui empat karya sastranya.

\section{Metode Penelitian}

Peneliti dalam penelitian ini menggunakan bentuk penelitian kualitatif deskriptif. Sumber data berupa pustaka empat karya sastra berbentuk gancaran 'prosa' karya Ki Padmasusastra yaitu (1) Serat Rangsang Tuban merupakan naskah Jawa dengan huruf Jawa cetak diterbitkan oleh N.V. Budi Utama di Surakarta (1912), (2) Serat Prabangkara merupakan naskah Jawa dengan huruf Jawa cetak diterbitkan oleh Tan Khoen Swie, Kediri (1921), (3) Serat Kandha Bumi merupakan naskah Jawa dengan huruf Jawa cetak diterbitkan oleh Tan Khoen Swie, Kediri (1924), serta (4) Serat Kabar Angin (1902) berupa naskah Jawa cetak diterbitkan oleh Vogel van der Heyde \& Co, Surakarta. Sehubungan dengan sumber data dalam penelitian ini masih dalam bentuk tulisan Jawa, maka perlu dialihaksarakan terlebih dahulu ke dalam tulisan Latin. Keempat naskah yang menjadi sumber data ini merupakan naskah koleksi Yayasan Sastra Lestari di Surakarta.

Data berupa data kebahasaan yang berwujud kata-kata yang mengandung bunyi-bunyi tertentu, kata bentukan, kelompok kata, kalimat-kalimat, gaya bahasa yang memperlihatkan gagasan multikultural yang multidimensional Ki Padmasusastra dalam empat karya sastranya yaitu dalam Serat Rangsang Tuban, Serat Prabangkara, Serat Kandha Bumi, dan Serat Kabar Angin. Teknik pengumpulan data dengan content analysis. Proses analisis data dalam penelitian ini bersifat interaktif, yaitu analisis data dengan menggunakan langkah-langkah: reduksi data, sajian data, dan penarikan kesimpulan.

\section{HASIL PENELITIAN DAN PEMBAHASAN}

Empat karya sastra tersebut merupakan sastra multikultural yang multidimensional. Sebagai sastra multikultural Serat Rangsang Tuban, Serat Prabangkara, Serat Kandha Bumi dan Serat Kabar Angin mampu mengekspos budaya Jawa lokal sebagai salah satu keberagaman budaya nasional dan mampu memberikan kontribusi pengayaan budaya global. Empat karya sastra Ki Padmasusastra yaitu Serat Rangsang Tuban, Serat Prabangkara, Serat Kandha Bumi 
dan Serat Kabar Angin memiliki kompleksitas nilai budaya yang jarang ditemukan dalam karya sastra lain.

\section{a. Dalam Serat Rangsang Tuban}

Serat Rangsang Tuban berikut ini memperlihatkan diksi yang berupa pandangan multikultural Ki Padmasusastra yang dilukiskan lewat kisah Raden Udakawimba di desa Sumbereja bersama ayah angkatnya yaitu Kyai Ageng Wulusan.

(1) Radèn Udakawimba kados rinujit kèngêtan sariranipun dhumawah ing papa sande dados gêgadhanganing satriya ingkang binadhe raja, ing wanci bakda sêmbahyang ngisa nilapakên ingkang rama kesah nênêpi dhatêng ing rêdi kados sabênipun...(SRT/77)

'Raden Udakawimba seperti tercabik-cabik hatinya teringat dirinya jatuh sengsara dan gagal menjadi kesatria yang akan dinobatkan menjadi raja, selesai sembahyang Ngisa pergi meninggalkan ayahnya untuk menyepi di gunung seperti kebiasaan setiap harinya...'

Teks di atas membuktikan bahwa Ki Padmasusastra kehidupan Kejawen sangat kuat dalam dirinya. Alam kejawen dan lingkungan kultural pemeluk agama Islam di mana dia hidup sangat mempengaruhi pola pikirnya. Raden Udakawimba sebagai pemeluk agama Islam yang taat dan selalu melaksanakan sembahyang Ngisa, akan tetapi ia masih sering mengadakan ritual yaitu nênêpi dhatêng ing rêdi 'menyendiri ke gunung'. Dua kultur yaitu Kejawen dan Islam dipadukan oleh Ki Padmasusastra tanpa harus dipertentangkan satu sama lain.

Dengan demikian Ki Padmasusastra sebagai orang Jawa mampu mengembangkan identitas budayanya tanpa saling mengganggu dan bahkan beliau berhasil memadukan dua kultur budaya yang berbeda tersebut (Kejawen dan Islam) sehingga dapat dimanfaatkan secara lebih baik.

Diksi mengenai pandangan multikultural lainnya dalam Serat Rangsang Tuban yaitu ketika Ki Padmasusastra menceritakan pasukan dari Banyubiru yang menyerang beteng Raden Udakawimba dengan menggunakan balon-balon udara. Pasukan udara yang mempergunakan balon-balon udara ini tidak pernah ada di pulau Jawa atau cerita-cerita pada masa lampau.

(2) sang prabu kandhêg wontên ing jawi, panggalihipun sang prabu wadyabalanipun amêsthi badhe nêmahi risak bilih pangrêbating balowarti namung kalayan wantah kemawon, gampil tinumpês ing gurnat gutuk api dening kêpapan wontên ing margi sungil. Sang prabu lajêng ambudi sarana ingkang kenging kadamêl gêlar garudha nglayang, lajêng adhedhawuh yasa palwa udara, bakalipun motha kinêlam ing wêsi janur, ingêsapan saking latu balêdhèg, sagêd mumbul ing gêgana, sarêng sampun samêkta lajêng katumpakakên para prajurit pêpilihan sami asikêp dêdamêl, ...(SRT/110)

'Sang prabu berhenti di luar, dalam hatinya sang prabu memastikan bahwa prajuritnya akan menemui kekalahan jika merebut beteng dengan cara biasa, mudah ditumpas oleh meriam-meriam api yang berada di tempat tinggi. Sang prabu lalu mencari sarana dengan membuat siasat perang garudha nglayang, dan segera memerintahkan membuat kapal udara, dengan bentuk seperti payung dengan kerangka dari besi, diasapi dengan uap api sehingga bisa melayang di udara, sesudah siap segera dinaiki oleh para prajurit pilihan dengan senjata lengkap'.

Berdasarkan kisah di atas, bahwa Ki Padmasusastra mampu membuat originalitas dalam ceritanya. Prabu Wayi dari Banyubiru ingin mengalahkan benteng pertahanan Sumbereja yang sangat tinggi dan kuat. Untuk dapat melewati benteng itu, maka perlu membuat peralatan perang berupa balon udara yang bisa mengangkut prajurit dan dapat membubung tinggi ke atas. Dengan 
balon udara tersebut, akhirnya Banyubiru bisa mengalahkan Sumberreja yang dipimpin oleh Raden Udakawimba.

Kemampuan mengadopsi ide baru dalam bentuk cerita yaitu penggunaan diksi balon-balon udara tersebut dipengaruhi oleh pengalaman beliau yang pernah ke negeri Belanda dan persahabatannya dengan orang-orang Belanda. Ki Padmasusastra dipertemukan dengan sinyosinyo Belanda seperti Van der Pant, H.A. De Nooy, A.H.J.G. Walbeehm, J.A. Wilkens, G.A.J. Hazeu, H.N. Kilian, dan F.L.Winter. Hubungan dengan tokoh-tokoh Eropa yang cukup akrab dan bahan bacaan yang luas begitu berpengaruh kepada Ki Padmasusastra untuk membuat rekonstruksi kritis cerita-cerita di Jawa Di sisi lain, pergumulan Ki Padmasusastra dengan karyakarya Mangkunegara IV dan Pakubuwana IX, dan terlebih dengan karya-karya pujangga Ranggawarsita (gurunya) tetap memberi muatan warna lokal yang kental.

Sastra multikultural tidak lepas dari gagasan multikultural yang melatarbelakangi lahirnya Serat Rangsang Tuban, Serat Prabangkara, Serat Kandha Bumi dan Serat Kabar Angin. Ki Padmasusastra telah menunjukkan bahwa beliau memiliki hak untuk mengekspresikan identitas kebudayaan modern secara demokratis dengan tidak meminggirkan identitas budaya lokal Jawa. Ki Padmasusastra sebagai orang Jawa berhak menunjukkan identitas budayanya dan mengembangkannya tanpa saling mengganggu dan bahkan beliau berhasil memadukan dua budaya yang berbeda sehingga memiliki manfaat yang lebih baik.

\section{b. Dalam Serat Prabangkara}

Ki Padmasusastra mampu mengekspos budaya Jawa lokal dan dipadukan dengan pandangan-pandangan yang lebih modern.

Diksi yang berupa gagasan multikultural dalam Serat Prabangkara adalah bahwa seorang putera mahkota sebenarnya tidak boleh menikah dengan gadis rendahan. Putera mahkota harus menurut kepada kedua orang tuanya. Akan tetapi Ki Padmasusastra melontarkan pemikiran baru atau kritikan. Jika di Jawa biasanya seorang anak menurut kepada orang tua, berbeda dengan budaya Barat. Seseorang anak bisa menolak kehendak orang tua dengan sopan dengan mengutarakan berbagai alasan yang masuk akal. Diksi ini merupakan pemikiran baru dalam budaya Jawa yang tidak pernah ada sebelumnya.

(3) Apa durung sira surupake yèn putraning ratu ora kêna krama olèh wong cilik, kudu olèh putrining ratu, utawa olèh santana putrane wong gêdhe têdhaking karaton, awit bakal dadi sêsêmbahane wong akèh.

Kawula nuwun sampun botên kêkirangan anggèn kawula anyêrêp-nyêrêpakên sarta mardi piturutipun dhatêng panjênêngan dalêm, ananging tansah wangkot, namung ngagêm karsanipun piyambak mawi nyorahakên kêkajênganing tiyang botên kenging pinêksa ing liyan, sanadyan ratu botên wênang amêksa dhatêng tiyang ingkang lumuh: utawi botên ajêng, upami kalampahan karsaning ratu ingkang makatên wau, punika nyulayani kalayan pranataning agama, prasasat mêksa akèn nêdha têtêdhan ingkang dipun gigoni, sanadyan ratu wau têtiyang sêpuhipun inggih ugi botên kenging dening amung dados jalaran, têtêp gêsanging manungsa mocung piyambak-piyambak ing pangayunanipun Pangeran (SP/6-7) 'Apa belum kamu jelaskan jika anak raja tidak boleh menikah dengan rakyat kecil, harus menikah dengan putri raja juga, atau kerabat anak dari pembesar keturunan keraton, sebab akan menjadi sesembahan orang banyak.

Saya sudah melakukannya dan tidak kekurangan cara untuk menjelaskan dan supaya mengikuti semua perintah dari sang raja, tetapi selalu membantah mengikuti keinginannya sendiri dan sang pangeran malah memberi petuah bahwa keinginan orang tidak boleh 
dipaksakan, walaupun raja memiliki kewenangan, tetapi keinginan sang raja tersebut tidak sesuai dengan peraturan agama, seperti memaksa untuk memakan makanan yang sudah dimutahkan, walaupun raja tersebut orang tuanya sendiri, tetap bahwa hidup manusia di bawah kekuasaan Tuhan'.

Teks di atas menunjukkan bahwa Pangeran Prabangkara terpaksa menolak keinginan ayahnya karena memang tidak sesuai dengan hati nuraninya. Hal ini menurut Pangeran Prabangkara sangat bertentangan dengan nilai-nilai moralitas dan bertentangan dengan nilai agama. Jika di Jawa terdapat konsep Dewa Raja atau raja sebagai wakil Tuhan dan semua perintahnya tidak boleh dilanggar, maka melalui Serat Prabangkara ini membuktikan bahwa pemikiran multikultural sudah mempengaruhi diri Ki Padmasusastra. Suatu keberanian yang jarang ditunjukkan oleh seorang pengarang pada waktu itu yang sebenarnya berupa kritikankritikan terhadap pemerintah. Peran dan karyanya telah menorehkan sejarah bagi perkembangan kebudayaan Jawa. Masa-masa pergaulannya dengan orang-orang Belanda itu memang memberikan arti tersendiri bagi Ki Padmasusastra.

(4) He, sakèhe putra santananingsun, muwah abdiningsun bumi ing Indhu, sarta satalatahe kabèh, samurcane putraningsun kaki adipati, wêwênanging paprentahan kadipatèn ingsun asta dhewe, saupama kaki adipati kabanjur ora ana timbule nganti panjênêngan ingsun murud ing jaman kalanggêngan, putra-putraningsun kakung ora ana kang ingsun lilani gumanti ing karaton ingsun, karsaningsun, kacêkêla marang sawijining putra santananing karaton saka pamilihe wong akèh, kang ingaran bêcik dhewe, bisa angenaki lan angayomi marang atine wong Indhu, samono iku mawa watêsan, lawaslawase mung limang taun, kajaba saka karêpe wong cilik kudu anjaluk salin sadurunge limang taun, utawa anjaluk lêstarine sawise limang taun, ...(SP/18-19)

'Wahai semua putra dan keluargaku, serta abdiku di bumi Indhu, serta rakyat di wilayahku, setelah kepergian anakku, kekuasaan pemerintahan aku pegang sendiri, jika ternyata sudah meninggal, anak-anakku laki-laki tidak ada yang saya ijinkan untuk menduduki karatonku, keinginanku, pemerintah dipegang oleh salah satu keluarga keraton karena memang dipilih oleh rakyat banyak, dan harus yang terbaik, bisa melindungi orang Indhu, dan ada batasannya, paling lama hanya lima tahun, kecuali atas keinginan rakyat kecil meminta ganti sebelum lima tahun, atau meminta diperintah lagi setelah lima tahun...'

Teks di atas memperlihatkan diksi mengenai pemikiran Ki Padmasusastra yang multikultural. Jika sebelumnya kekuasaan raja sangat tidak terbatas, maka oleh Ki Padmasusastra pemikiran tersebut dirubah. Suatu pemahaman baru yang lebih modern mulai ditanamkan oleh Ki Padmasusastra terhadap bangsa Jawa pada waktu itu. Raja yang berkuasa hendaknya benarbenar pilihan rakyat banyak. Pemerintahan seorang raja pun ada batasnya kurang lebih hanya selama lima tahun dan itu dapat dipilih kembali jika rakyat menyetujuinya. Ki Padmasusastra berani melontarkan kritikan atau gagasan yang dianggap modern pada waktu itu kepada pemerintah lewat Serat Prabangkara ini.

\section{c. Dalam Serat Kandha Bumi}

Diksi mengenai pandangan multikultural dalam Serat Kandha Bumi ditunjukkan ketika Puthut Sapatitala dan Endang Siti Pasir diambil anak oleh Pandhita Lebu Pasir di Redi Pasir dan diajari berbagai ilmu pengetahuan untuk bekal hidup. Dalam cerita Serat Kandha Bumi ini sangat terlihat pandangan Ki Padmasusastra yang sangat menekankan pentingnya pendidikan atau sekolah bagi anak-anak. 
(5) Kacariyos lare kêkalih winimbasara wontên ing pratapan, dinusan ing toya gege enggal agêng, kalis ing sêsakit, kalajun agêngipun, sasampunipun wanci ngumuripun pinrêtêk ing piwulang dening Sang Pandhita, lare kêkalih landhêp-landhêp manahipun kados lare kajiman, sabarang ingkang dipun wulangakên sagêd kalêbêt, alus bêbudènipun dhasar limpad ing panggraita sagêd ngêmpakakên dugi prayogi, kasok sihipun Sang Pandhita, ...(SKB/14)

'Diceritakan kedua anak dididik di pertapaan, ibaratnya seperti dimandikan di air yang dipergunakan untuk memandikan bayi, segera menjadi besar, jauh dari penyakit, setelah berumur keduanya diberi pelajaran oleh sang pendeta, kedua anak itu pandai dan tajam hatinya, semua yang diajarkan bisa masuk, halus budi pekerinya, pandai dalam pemikiran dan bisa memilah baik dan buruk, sangat dikasihi oleh sang pendeta...'

Ki Padmasusastra secara eksplisit mengungkapkan fakta pembaruan dalam Serat Kandha Bumi ini dengan memunculkan tema pendidikan. Sikap pengarang sangat terlihat jelas bahwa ia mementingkan ilmu pengetahuan. Hal ini sangat dipengaruhi oleh zaman ketika Ki Padmasusastra hidup. Masa-masa pergaulannya dengan teman-teman dari Belanda memberikan arti tersendiri bagi Ki Padmasusastra bahwa penguasaan ilmu pengetahuan sangat penting. Terutama untuk bangsa yang terjajah, agar tidak dibodohi oleh bangsa Asing maka semua rakyat harus bisa mengenyam pendidikan dari yang terendah sampai yang tertinggi.

Serat Kandha Bumi menceritakan bahwa pendidikan yang diberikan oleh Pendeta Lebu Pasir tidak hanya diberikan kepada Raden Sapartitala saja, tetapi Endang Siti Pasir juga mendapat pendidikan yang sama dan disesuaikan dengan sifatnya sebagai seorang wanita. Hal ini merupakan salah satu ide pembaruan atau kritikan yang dilontarkan oleh Ki Padmasusastra. Selama ini pendidikan hanya bisa dinikmati oleh anak laki-laki saja, akan tetapi Ki Padmasusastra sudah menggambarkan bahwa pendidikan terhadap kaum perempuan juga sangat penting. Di Eropa pada waktu itu, para sarjana tidak hanya didominasi oleh kaum laki-laki saja, tetapi kaum perempuan juga sudah banyak yang mengenyam pendidikan setara dengan kaum laki-laki. Kenyataan ini sangat berbeda dengan di Jawa.

Diksi mengenai gagasan multikultural selanjutnya dalam Serat Kandha Bumi adalah sikap Raden Sapartitala yang ingin pergi dari pertapaan untuk mengabdikan ilmu pengetahuan yang ia miliki untuk kepentingan orang banyak. Gagasan yang luar biasa dari Ki Padmasusastra yang ditunjukkan oleh Serat Kandha Bumi ini menyadarkan manusia bahwa penyebarluasan ilmu pengetahuan sangat penting.

(6) Pukulun, ila-ila punapa ingkang kula panggih bilih kula botên prasaja kadangu sang panêmbahan, sajatosipun manah kula awrat mati raga wontên ing pacrabakan, dene kaprawiran kula pêparingipun eyang badhe ical tanpa lari, kêpêndhêm wontên ing balubukanipun latu pamujan, lêstantun ngantos dumugi ing pêjah, dados badhe tanpa tilas mênggah ing gêsang kula, kula nuwun eyang, mênggah ingkang dados kajêng kula ingkang kalayan idi paduka, kula badhe suwita ing panjênêngan ratu, sokur bage sèwu katarimah pasuwitan kula, sagêd dados punggawaning praja, punika eyang ingkang dados losing kajêng kula,...(SKB/15-16)

'Sesembahanku, kesulitan apa yang akan saya temui ketika saya tidak berterus terang atas pertanyaan sang panembahan, sebenarnya hatiku berat ketika bertapa di pertapaan, dan ilmu kebaikan atas pemberian kakek akan hilang tanpa bekas, terpendam di dalam abu api pemujaan, langgeng sampai saya meninggal, jadi akan menjadi tanpa bekas hidupku ini, saya memohon kakek, adapun yang menjadi niatku dengan ijin kakek, saya akan mengabdi 
kepada raja, mudah-mudahan diterima pengabdianku, bisa menjadi pegawai di kerajaan, inilah kakek yang menjadi keinginanku,...'

Sarjana-sarjana Eropa ketika Ki Padmasusastra hidup senang mempelajari bahasa dan sastra Jawa. Mereka mempelajari bahasa dan sastra Jawa melebihi orang-orang Jawa yang belajar bahasa dan sastra Jawanya sendiri. Kepandaian mereka akan bahasa Jawa melebihi kepandaian orang-orang Jawa sendiri. Sebaliknya orang-orang Jawa malah menonjolkan tulisantulisan asing dan tidak percaya pada ajaran-ajaran Mangkunagara IV, Ranggawarsita dan sebagainya. Kondisi seperti ini menimbulkan keprihatinan pada diri Ki Padmasusastra sehingga timbul niatnya untuk mengarang buku-buku yang bisa mencerdaskan kehidupan bangsanya pada waktu itu.

Diksi Ki Padmasusastra lainnya dalam Serat Kandha Bumi adalah cerita tokoh Endang Siti Pasir dan Raden Sapartitala yang merupakan anak orang biasa, akhirnya bisa menjadi pemimpin negara. Endang Siti Pasir akhirnya menjadi permaisuri oleh Maha Prabu Sultan Mangkubumi, dan kakaknya yaitu Raden Sapartitala menikah dengan Dewi Pratiwi atau diangkat menjadi menantu Patih Janaloka di negara Bantara Rengka. Ide baru bahwa pada jaman dahulu rakyat jelata tidak mungkin menjadi seorang pemimpin, akan tetapi Ki Padmasusastra mencoba merubah pola pikir masyarakat pada jamannya bahwa seseorang dari rakyat jelata pun apabila memiliki kemampuan sebenarnya bisa menjadi seorang pemimpin seperti keturunan-keturunan bangsawan atau raja.

(7) Sang Prabu saya waspada yèn Radèn Sapartitala mumpuni dhatêng kawignyan, botên antawis lami, lajêng winisuda dados mantri anom lêbêt, sarta lajêng kakarsakkên andhèrèk tindakipun Sang Nata dhatêng gêdhong pangrêmbagan prakawis nagari kaliyan Kyai Patih sarta para nayakaning praja, Radèn Sapartitala kalilan usul pamanggihipun. Pintên-pintên prakawis ingkang ruwêt dados wudhar, ingkang pêtêng dados padhang dening pamanggihipun Radèn Sapartitala, ....(SKB/5-26).

'Sang prabu semakin memperhatikan jika Raden Sapartitala pandai dalam hal kepandaian. Tidak lama, segera diangkat menjadi mantri anom lebet, serta diminta mengikuti kemauan sang raja ke gedung pertemuan yang biasa dipergunakan untuk membicarakan hal-hal yang berhubungan dengan pekerjaan negara beserta sang patih dan para menteri negara, Raden Sapartitala diterima usul-usulnya. Berbagai perkara yang sulit menjadi terbuka, yang gelap menjadi terang oleh pemikiran Raden Sapartitala...'

(8) Kacariyos Sang Prabu sampun andhawuhakên dhatêng Kyai Patih Janaloka, putranipun èstri Rêtna Pratiwi kapundhut badhe katarimakakên dhatêng Radèn Sapartitala sarta kadhawuhan samêkta bawahaning pikramèn....(SKB/32).

'Diceritakan bahwa sang raja sudah memerintahkan kepada Kyai Patih Janaloka bahwa anaknya perempuan yaitu Retna Pratiwi diminta sang raja untuk dinikahkan dengan Raden Sapartitala serta diperintahkan menyiapkan semua keperluan pernikahan...'

(9) Sang Prabu matur dhatêng ingkang eyang raja putri wrêdha, Pukulun, ingkang asoca bathara, sanadyan karêntêging manah kula sampun kauningan, nanging subasitaning basa: kula kêdah amêdharakên raosing manah kula ingkang sampun kauningan salêbêting batos, kula nyuwun pitakèn, yayi dèwi ingkang kula tutakên saking sêndhang wau: punapa wayahipun kangjêng eyang, sarta punapa sampun winêngku ing 
priya. ...Kangjêng eyang, kula branta dhatêng lare wau, mênawi saèstu taksih lamban, kula suwun kaparênga dados sori kula,... (SKB/44).

'Sang raja berkata kepada nenek tua raja, gusti, yang seperti batara, walaupun keinginan saya sudah diketahui, tetapi tatakrama dalam berbahasa: saya harus mengatakan rasa hati saya yang sudah anda ketahui dalam hati saya, saya mau bertanya: adikiku sang dewi yang saya ikuti dari kolam tadi: apakah cucu kangjeng eyang, serta apakah sudah dinikahi oleh seorang pria....Kangjeng eyang, saya jatuh cinta kepada anak itu, kalau masih sendirian, saya minta diijinkan untuk menjadi permaisuri saya...'

Pola pikir atau gagasan yang baru ini sangat jarang ditemui di dalam karya sastra. Model kekuasaan di Barat tidak seperti di Jawa. Di pulau Jawa, kepemimpinan selalu dipegang oleh orang-orang yang menjadi ahli warisnya. Sekolah-sekolah hanya diperuntukkan bahwa para pejabat Belanda dan pembesar-pembesar pribumi, rakyat kecil jarang yang bisa mengenyam pendidikan di sekolah. Hal inilah yang membuat keprihatinan Ki Padmasusastra dan oleh karena itu beliau membuat Serat Kandha Bumi yang sebenarnya ingin mengingatkan kepada pembaca bahwa keturunan rakyat biasa pun bisa menjadi pemimpin jika memiliki kemampuan yang baik.

Seorang pejabat kadangkala tidak mau pernah dikritik oleh rakyatnya atau bawahannya. Ajaran bagaimana seorang pejabat harus memahami bahwa ia tidak bisa lepas dari kritikan para bawahannya termuat dalam Serat Kandha Bumi sebagai berikut.

(10) Gusti, saking pangèstu paduka kawula sampun sagêt ngangge kalakuwan santosa, kawula botên bingah kaalêm padamêlan kula lêpat, kosok wangsulipun botên susah kacacad padamêlan kawula lêrês, ananging loking jana punika ingkang kêdah kawula kawekani, sok sampuna panjênêngan paduka anguningani ciptaning manah kawula, dados badhe botên kagèt suraking tiyang kathah ingkang sami nyantên awon kawêntar sagêd nêmpuh kapiyarsa ing panjênêngan paduka, punika ingkang sagêd anipisakên pasuwitan, ical piyandêlipun tiyang sanagari, punapa bilih panjênêngan paduka keguh dhatêng panyantun awon saha cêcampah wau punika....(SKB/31-32)

'Gusti, atas doa anda saya sudah memakai tingkah laku yang baik, saya tidak senang disanjung ketika pekerjaan saya salah, atau sebaliknya tidak bersedih dicemooh jika pekerjaan saya benar, akan tetapi kritikan orang banyak inilah yang saya pegang, jika anda telah mengetahui semua pikiran di hati saya, dengan demikian tidak akan terkejut atas suara orang banyak yang menyuarakan semua kejelekan dan akhirnya sampai terdengar ke hadapan anda, inilah yang bisa menggugurkan pengabdian, hilang kepercayaan semua rakyat di negara, atau sang raja mempercayai kepada suara-suara yang tidak baik tersebut...'

Teks di atas adalah salah satu diksi yang berupa ide multikultural yang ingin disuarakan oleh Ki Padmasusastra. Seorang pejabat negara tidak akan lepas dari sorotan rakyat banyak. Jika seorang pejabat bersalah, ia harus mengakui kesalahannya dan kekurangannya. Kritikan ini ditulis sebagai bentuk reaksi atas kondisi jaman pada saat Ki Padmasusastra hidup. Pejabatpejabat yang ada pada waktu Ki Padmasusastra hidup sangat jarang yang mau menerima kritikan dari rakyatnya atau pejabat yang lain. Kondisi seperti ini ingin diluruskan oleh Ki Padmasusastra melalui Serat Kandha Bumi ketika Raden Sapartitala akan diangkat menjadi menantu sang patih dan semestinya mendapat kedudukan jabatan yang lebih tinggi di negara Bantala Rengka.

Diksi berupa ide-ide multikultural dari luar yang dikemas sedemikian rupa oleh $\mathrm{Ki}$ Padmasusastra ini sangat jarang ditemukan dalam karya milik orang lain. Keberanian Ki 
Padmasusastra menyuarakan ide-ide baru dari luar atau kritikan atas kondisi jaman yang ada menyebabkan Ki Padmasusastra memiliki kekhasan tersendiri jika dibandingkan dengan pengarang lain.

Diksi mengenai gagasan multikultural lainnya yaitu pernikahan Maha Prabu Mangkubumi seorang raja besar di negara Bantala Rengka dengan Endang Siti Pasir yang merupakan rakyat jelata. Cerita ini sebenarnya gagasan baru di tanah Jawa, bahwa seorang raja juga bisa menikah dengan rakyat biasa. Rakyat biasa juga memiliki hak yang sama dan bisa diangkat menjadi permaisuri. Jika dalam pandangan sebelumnya bahwa raja adalah wakil dewa, semua keputusannya tidak boleh dibantah, raja tidak pernah bersalah, isteri raja seharusnya juga seorang putera raja atau bangsawan, maka pandangan-pandangan itu oleh Ki Padmasusastra dicoba untuk diubah ke pandangan yang lebih modern. Gagasan multikultural yang dilontarkan oleh Ki Padmasusastra dan tidak biasa ditemukan di tanah Jawa ini ternyata menarik dan mengukuhkan $\mathrm{Ki}$ Padmasusastra sebagai seorang pengarang yang mampu menyuarakan isi hati dan ketidakadilan pada jamannya.

Diksi Ki Padmasusastra yang juga menarik dalam Serat Kandha Bumi adalah adanya ide baru mengenai pengangkatan harkat martabat seorang wanita. Dalam serat ini jelas kedudukan seorang wanita sangat ditinggikan oleh Ki Padmasusastra. Endang Siti Pasir yang memiliki budi pekerti yang baik akhirnya dinikahi oleh Maha Prabu Mangkubumi. Wanita dalam Serat Kandha Bumi tidak direndahkan. Penyanjungan atas kecantikan seorang wanita, meninggikan harkat martabatnya merupakan sesuatu yang sangat baru pada jaman Ki Padmasusastra. Kebanyakan wanita Jawa pada masa lampau harus selalu menuruti keinginan orang tua, kurang berpendidikan, maka Ki Padmasusastra ingin mencoba merubah pandangan-pandangan kuna ini. Walaupun wanita selalu dipuja, bisa sejajar dengan pria, akan tetapi penghormatan seorang wanita terhadap suami, penghormatan kepada orang lain tetap diutamakan. Sebagai wanita Jawa, ia harus tetap memperhatikan etika dan kesopanan yang berlaku di Jawa.

\section{d. Dalam Serat Kabar Angin}

Diksi Ki Padmasusastra mengenai perlunya pendidikan seorang wanita juga tertera dalam Serat Kabar Angin. Dalam serat ini jelas kedudukan seorang wanita sangat ditinggikan oleh Ki Padmasusastra. Dewi Sumilir puteri dari Dewi Maruti dan Pangeran Pracondha sejak kecil telah diberikan pendidikan yang sama dengan laki-laki.

(11) sang putri wiwit timur ngantos diwasa pinrêtêg ing piwulang wontên ing pawiyatan agêng gurunipun kawan likur, sang putri sampun lêbda dhatêng têmbung sarta sastra Kawi Kêling,...(SKA/87).

'Sang putri sejak kecil sampai dewasa selalu diajari pelajaran seperti di sekolah-sekolah yang besar dan memiliki guru dua puluh empat, sang putri sudah paham mengenai kaa-kata dan sastra Kawi Keling...'

Di Barat, kaum wanita memiliki hak yang sama dalam memperoleh ilmu. Akan tetapi di Jawa pada jaman itu, kaum wanita belum banyak memperoleh pendidikan yang setara dengan kaum laki-laki. Melalui dikis-diksi di atas, sebenarnya Ki Padmasusastra selalu mengajak kepada pembaca bahwa pendidikan bagi kaum perempuan maupun laki-laki sama pentingnya. Pendidikan akan menjauhkan bangsa dari kebodohan. Sebaliknya bangsa yang bodoh akan mudah dijajah oleh bangsa lain. Dengan demikian gagasan baru di Jawa yang dilontarkan Ki Padmasusastra melalui cerita ini merupakan salah satu kekhasan beliau di dalam mengarang Serat Kabar Angin. 
Demikian pula cucunya yaitu Dewi Bantarangin juga mendapat pelajaran dari para gurunya agar ia menjadi wanita yang pandai, halus budi pekertinya dan mampu menjadi pemimpin yang baik.

(12) Kacariyos Dèwi Bantarangin kados lare kajiman, limpad ing panggraita, kalêbêtakên ing pawiyatan agêng pinrêtêk ing piwulang warni-warni, gurunipun tigang dasa nêm, botên namung kawruh ing wanodya andondomi, nyulam, nênun, nyongkèt, ngalualam, dalasan kawruh ulah praja, ulah prang, anganggit-anggit putus sadaya...(SKA/128-129)

'Diceritakan Dewi Bantarangin seperti anak luar biasa, pandai dalam pemikirannya, dimasukkan ke sekolahan besar diberi beraneka macam pengetauan, gurunya berjumlah tiga puluh enam, tidak hanya pengetahuan untuk wania seperti merajut, menyulam, menyongke, dan tidak lupa ilmu pemerintaan, ilmu perang, mengarang pandai semua...'

Ki Padmasusastra merasa bahwa wanita pada saat itu sulit menikmati pendidikan yang setara dengan kaum laki-laki. Hal ini terbukti bahwa ada ide baru yang ingin diungkapkan oleh Ki Padmasusastra kepada bangsa Jawa pada waktu itu. Dewi Bantarangin puteri Sang Prabu Timur dengan Ibu Dewi Sumilir mendapat berbagai pengetahuan dari para gurunya baik keterampilan untuk kaum wanita maupun mengenai ilmu perang dan pemerintahan. Walaupun seorang wanita, kemampuan Dewi Bantarangin dikatakan kados lare kajiman, limpad ing panggraita. Dengan demikian Ki Padmasusastra ingin mengangkat kedudukan seorang wanita ke derajat yang lebih tinggi.

Diksi berupa ide multikulturalisme lainnya dalam Serat Kabar Angin bahwa ada usaha untuk memberikan pengaruh kepada bangsa Jawa pada waktu itu bahwa bekerja menjadi abdi pemerintah sangat dibatasi oleh peraturan. Seorang abdi hanya akan selalu diperintah oleh raja, dan tidak memiliki kekuasaan apapun.

Teks di atas memperlihatkan sikap Ki Padmasusastra bahwa bekerja menjadi abdi pemerintah selalu dibayang-bayangi ketakutan karena harus tunduk pada peraturan yang dibuat oleh pemerintah dan tidak memiliki kekuasaan. Berbeda halnya dengan seorang pedagang, ia bebas mengatur bawahannya dan tidak terikat dengan siapapun. Seorang pedagang bahkan bisa pergi kemana pun yang ia kehendaki. Jika seorang raja selalu memikirkan uang untuk membayar upah kawulanya, berbeda dengan seorang pedagang sebab ia hanya mengatur datangnya uang.

(13) wong sugih dhuwit iku pangwasane ana sadhuwuring ratu, mulane aku bakal ngawula ing dhuwitku bae, supaya pangwasaku luwih saka rama prabu, ratu tansah susah anggalih wêtuning balanjane kang didhahar ing sabên taun, sarta balanjane ingkang para abdi, luwih susah manè yèn mêtokake wragading prang, prasasat dhuwit disêbar ing laut, beda bangêt karo wong among dagang marentah wong mung sacukupe, dadi ing sakarêpe, kabèh uwong prasasat kêna pinarentah, jajah mênyang êndi-êndi ora ana sing malangi, cêkake kêna ingaranan dununging kamuktèn iku mung ana kapila....(SKA/129-130)

'Orang yang kaya uang kekuasaannya di atas seorang raja, oleh karena itu aku akan mengabdi kepada uangku saja, supaya kekuasaanku melebihi dari ayahanda, raja selalu sedih memikirkan keluarnya uang belanja yang akan dimakan setiap tahun, serta upah belanja untuk para abdi, lebih susah lagi jika mengeluarkan biaya untuk perang, seperti menebar uang di lautan, berbeda dengan seorang pedagang yang memerinta orang secukupnya, dengan demikian sekehendak hatinya, semua orang seolah-olah bisa diperintah, pergi kemana-mana tidak ada yang menghalangi, secara singkat bahwa keberadaan kemakmuran hanya berada pada diri seorang saudagar...' 
Inilah suatu bukti adanya ide baru dari Ki Padmasusastra pada waktu itu. Dalam teks tersirat ide bahwa di samping seorang raja dan priyayi, sebenarnya ada kelas baru pada waktu itu yaitu kelas pedagang. Ki Padmasusastra terlihat lebih menyukai jiwa seorang sudagar daripada ia menjadi abdi pemerintah. Pemikiran kepada bangsa Jawa agar lebih banyak untuk among dagang atau menjadi saudagar tersebut telah tergambar dalam Serat Kabar Angin. Jika selama ini raja dan priyayi atau bangsawan yang selalu tampil di depan, maka Ki Padmasusastra melontarkan gagasan bahwa seorang saudagar atau pedagang juga bisa tampil untuk berperan dan ikut memajukan bangsa dan negara.

Diksi yang unik dari Ki Padmasusastra lainnya bahwa walaupun dia pernah dipecat sebagai seorang abdi dalem, ternyata kekaguman atas diri seorang raja masih sangat kuat dalam diri Ki Padmasusastra. Jika sebelumnya ada ide baru dari Ki Padmasusastra bahwa di samping seorang raja dan priyayi, ada kelas pedagang dan seorang pedagang memiliki kebebasan tersendiri, maka Ki Padmasusastra juga masih mengakui bahwa raja atau pemimpin yang baik masih sangat dibutuhkan oleh semua orang.

(14) wiwit punika sang pangeran sumêrêp dhumawahing bilai agêng ingkang kasandhang amargi saking kasugihanipun, sarta sumêrêp yèn pituturipun ingkang rama awanti-wanti ingkang tansah dipun tulak, punika lêrês sadaya, punapadene sumêrêp yèn kaluhuraning panjênêngan nata beda utawi dede iribanipun kalihan kaluhuraning sudagar sugih, awit têntrêming sudagar namung bilih kaayoman prabawaning ratu wontên salêbêting nagari, sudagar ingkang sawêg alêlayar kados sariranipun tanpa aji pisan-pisan, gampil rinampas ing bajag, beda kalihan panjênêngan ratu ingkang alêlayar andon prang, kajèn kèringan ing saênggèn-ênggèn...(SKA/158-159)

'Mulai saat ini sang pangeran mengetahui bahwa kesialan yang dialami sebab karena kekayaannya, serta mengetahui perkataan sang ayah yang selalu ditolaknya, ini semua benar, serta mengetahui bahwa kebesaran seorang raja berbeda dan tidak sama dengan keluhuran pedagang yang kaya, sebab ketenteraman seorang saudagar jika mendapat perlindungan dari raja di negara tersebut, saudagar yang sedang berlayar seperti dirinya tidak berharga sama sekali, mudah dirampok oleh bajak laut, berbeda dengan seorang raja yang berlayar untuk pergi berperang, dihormati di manapun berada...'

Walaupun pandangan Ki Padmasusastra sudah modern, akan tetapi penghormatan kepada diri raja dan pemimpin masih sangat melekat dalam dirinya. Pemimpin atau raja yang baik akan dapat melindungi seluruh rakyatnya jika ada musibah. Berbeda dengan seorang pedagang, walaupun dapat bepergian jauh dan tidak terikat oleh siapa pun, tanpa perlindungan dari negara dan raja yang memerintah, maka tidak mungkin pedagang atau rakyat di negara tersebut akan hidup dengan tenteram. Sungguh luar biasa pemahaman Ki Padmasusastra dalam memandang berbagai peristiwa pada jamannya.

Seseorang juga harus memiliki kepandaian dalam hidupnya seperti kisah Pangeran Prakempa. Dengan keahlian dan kepandaiannya, ia bisa melaksanakan pekerjaan yang diberikan Kyai Juragan Pancawora dan Nyai Juragan Pancawati.

(15) malah kyai juragan rumaos kawon wêgig, Jaka Bayu lajêng dipun kanthi dados kondhang nindakakên padamêlan awrat, lampahing sade tinumbas botên nate kablowok, lampahing tangguh awis mirahing dêdagangan, botên nate nguciwani, lampahing petang arta botên nate kisruh, awit saking punika adamêl rêntahing manahipun kyai sudagar,...(SKA/165). 
'Dan kyai juragan merasa kalah kepandaiannya, Jaka Bayu segera digandeng dan terkenal melaksanakan pekerjaan yang berat, jalannya perdagangan tidak pernah rugi, dalam menaksir murah dan mahanya barang dagangan tidak pernah mengecewakan, dalam penghitungan uang tidak pernah salah, oleh karena itu membuat semakin sayang kyai saudagar...'

Ketepatan berhitung, kecerdasan dalam memimpin bagi seorang pemimpin akan menjadikan ia berhasil dan mendapat pujian. Demikianlah cita-cita Ki Padmasusastra melalui cerita Serat Kabar Angin, yang sebenarnya sebagai bentuk kehati-hatiannya bahwa ia pernah terlibat hutang piutang dengan seorang Cina. Atas keteledorannya, ia akhirnya digugat oleh seorang Cina dan dipecat dari jabatannya sebagai abdi dalem. Peristiwa yang pernah dialaminya bersama orang Cina ini akhirnya membukakan pandangan Ki Padmasusastra bahwa kehatihatian, ketepatan dalam berhitung, kemampuan memimpin dalam berdagang seperti orang-orang Cina sangat penting untuk dimiliki orang-orang Jawa. Inilah pandangan multikultural yang mempengaruhi diri Ki Padmasusastra dan akhirnya diadopsikan dalam ceritanya.

Sikap kejawaan Ki Padmasusastra terlihat dalam diksi ketika Pangeran Prakempa atau Prabu Wrestibajra akan melamar Rara Erawati akhirnya gagal karena Rara Erawati marah dan pergi dari rumah. Hal ini disebabkan karena Prabu Wrestibajra belum meminta ijin kepada ayahnya yaitu Sang Prabu Timur bahwa ia menjadi raja dan belum meminta ijin kepada kakak perempuannya bawa ia akan menikah dengan Rara Erawati puteri Juragan Pancawora.

(16) sira sumurupa yèn karêpira palakrama andhisiki bakyunira, iku ora bênêr, awit bakyunira ora gèthèk ora ciri arêp sira langkahi, mulane sira kasiku ing dewa kang linuwih, ing mêngko sira muliha marang ing Marutamanda, nyuwuna ngapura marang ramanira kaki Prabu Timur sarta marang eyang-eyangira kakung putri, lan nyuwuna idi jumênêngira nata ana ing pulo Suwung, ...yèn sira ngèstokake sapawêkasku: amêsthi sira nêmu raharja. (SKA/257)

'Ketahuilah kamu bahwa keinginanmu menikah mendahului kakak perempuanmu, itu tidak benar, sebab kakakmu tidak cacat akan kamu dahului, karena itu kamu mendapat kutukan dewa, dan nanti segeralah kamu pulang ke Marutamanda, minta maaflah kepada ayahmu Prabu Timur serta kepada kakek dan nenekmu, dan mintalah ijin untuk menjadi raja di pulau Suwung, ...jika kamu melaksanakan petunjukku: pasti kamu akan menemui kebahagiaan'.

Pernikahan yang dilakukan oleh seorang adik dan mendahului kakaknya bagi masyarakat Jawa suatu bentuk pantangan. Kepercayaan ini sangat dipegang teguh oleh masyarakat Jawa. Hal ini mengisyaratkan bahwa Ki Padmasusastra sebenarnya ingin menonjolkan sisi budaya masyarakat Jawa dalam karya sastranya. Di samping pemikiran-pemikiran yang modern dan kadangkala tidak sesuai dengan budaya Jawa, di satu sisi ia tetap ingin mempertahankan eksistensi budaya Jawa di dalam karyanya. Sungguh suatu perpaduan cerita mengenai pemikiran yang jarang dilakukan oleh masyarakat Jawa pada jaman dahulu.

\section{SIMPULAN}

Pengungkapan budaya Jawa lokal dengan perpaduan budaya yang dianggap lebih modern mampu mencuatkan Serat Rangsang Tuban, Serat Prabangkara, Serat Kandha Bumi dan Serat Kabar Angin di tengah pluralisme budaya global. Dengan demikian lokalitas bukan sesuatu yang 
perlu dipertentangkan dengan globalitas, lingkungan eksternal yang plural, melainkan justru dapat memberikan pengayaan dan makna tersendiri kepada budaya lokal. Inilah keunggulan Serat Rangsang Tuban, Serat Prabangkara, Serat Kandha Bumi dan Serat Kabar Angin sebagai sastra multikultural yang multidimensional yang sarat makna kehidupan.

Pemikiran, kreativitas, maupun keteladanan semangat Ki Padmasusastra sebagai seorang pengarang telah berhasil membangun karakter bangsa karya sastra. Ki Padmasusastra juga mengajarkan pendidikan budi pekerti terutama melalui nilai-nilai universal, seperti rajin menuntut ilmu, bekerja keras, gotong royong, toleransi, maupun keramahan. Dalam karya sastra tradisional Jawa, nilai-nilai seperti itu seperti terserak keberadaannya. Oleh karena itu Ki Padmasusastra mencoba mengemas kembali nilai-nilai yang dapat dipergunakan untuk membangun karakter bangsa, tanpa menghilangkan kembali nilai-nilai kearifan lokal yang sudah ada. Gagasan multikultural Ki Padmasusastra dalam Serat Rangsang Tuban, Serat Prabangkara, Serat Kandha Bumi dan Serat Kabar Angin merupakan keunggulannya dan keorisinilannya karena sebagai pelopor bentuk karya sastra Jawa baru.

\section{Daftar Pustaka}

Mulyanto. 2003. Kerangka Pikir Padmasusastra tentang Tingkat Tutur Bahasa Jawa. Tesis S2. Program Pascasarjana UNS.

Padmasusastra. 1902. Serat Kabar Angin. Surakarta: Vogel van der Heyde \& Co. Surakarta. 1912. Serat Rangsang Tuban. Surakarta: n.v. Budiutama.

1921. Serat Prabangkara. Kediri: Tan Khoen Swie.

1924. Serat Kandha Bumi. Kediri: Tan Khoen Swie.

Padmosoekotjo. 1960. Ngengrengan Kasusastran Djawa I, II. Jogjakarta: Hien Hoo Sing.

Poerwadarminta, W.J.S. 1939. Baoesastra Djawa. Batavia: J.B. Wolter Uitgevers Maatchappij N.V. Groningen.

Supardi, Imam. 1961. Ki Padmasusastra Wong mardika kang marsudi kasusastran Djawa ing Surakarta. Sedjarahe, kawruhe, lan lelabuhane, tumrap basa lan kasusastran Djawa. Surabaya: Penerbit Panjebar Semangat.

Wibowo, Prasetyo A.W. 2010. Tatacara Kelahiran Masyarakat Jawa Menurut Serat Tatacara Karya Ki Padmasusastra hlm. 113-121. Proseding Seminar Nasional Demokratisasi Ki Padmasusastra dalam Bahasa, Sastra, dan Budaya. FSSR Publishing, Surakarta. 